\title{
Peptide substrates for chymosin (rennin)
}

\section{Interaction sites in $\kappa$-casein-related sequences located outside the (103-108)-hexapeptide region that fits into the enzyme's active-site cleft}

\author{
Servaas VISSER, ${ }^{*}$ Charles J. SLANGEN and Peter J. VAN ROOIJEN \\ Department of Biophysical Chemistry, Netherlands Institute for Dairy Research, P.O. Box 20, 6710 BA Ede, \\ Netherlands
}

\begin{abstract}
The role of individual amino acid residues in the 98-102 and 111-112 regions of bovine $\kappa$-casein in its interaction with the milk-clotting enzyme chymosin (rennin) was investigated. To this end the tryptic 98-112 fragment of $\kappa$-casein was modified in its $N$ - and/or $C$-terminal part by chemical (guanidation, ethoxyformylation, repeated Edman degradation) and enzymic (carboxypeptidase) treatments. Further, use was made of short synthetic $\kappa$-casein analogues in which His-102 had been replaced by Pro or Lys. All peptides and their derivatives were tested comparatively at various $\mathrm{pH}$ values for their ability to act as chymosin substrates via specific cleavage of the peptide bond at position 105-106. The results indicate that in the alternating 98-102 sequence (His-Pro-His-Pro-His) the His as well as the Pro residues contribute to the substrate activity with no predominant role of any one of these groups. Another interaction site is formed by the Lys residue at position 111 of the substrate. A model of the enzyme-substrate complex is proposed. Herein the 103-108 fragment of the substrate, to be accommodated within the enzyme's active-site cleft, is brought into position by electrostatic binding (via His-98, His-100, His-102 and Lys-111) near the entrance of the cleft. These interactions are strongly supported by Pro residues at positions 99, 101, 109 and 110 of the substrate, which act as stabilizers of the proper conformation of the substrate in the enzyme-substrate complex.
\end{abstract}

\section{INTRODUCTION}

The specific cleavage of $\kappa$-casein by chymosin (rennin, EC 3.4.23.4), which forms the first step in the milk-clotting process, has been the subject of numerous investigations (for a review see Dalgleish, 1982). Valuable information as to the importance of individual amino acid side chains in the vicinity of the chymosinsensitive Phe-Met bond of $\kappa$-casein was obtained from kinetic studies carried out at pH 4.7 with short, mostly synthetic, peptide substrates (Schattenkerk et al., 1971; Raymond et al., 1972; Visser et al., 1976, 1977, 1980; Raymond \& Bricas, 1979; Visser, 1981). Computermodelling studies of the three-dimensional structure of chymosin not only supported the general conclusions of these studies, but also provided more detailed information on the possible way of positioning of the various substrate residues within the enzyme's active-site cleft (B. L. Sibanda \& T. L. Blundell, unpublished work). The amino acid sequence of the region around the cleavable Phe-Met bond at position 105-106 of bovine $\kappa$-casein is as follows (Mercier et al., 1973):

at $\mathrm{pH} 4.7$ and $30^{\circ} \mathrm{C}$ ). Lengthening of the peptide chain at the $C$-terminal end did increase the substrate capacity to some extent [for $\kappa(103-112) k_{\text {cat. }} / K_{\mathrm{m}}=67 \mathrm{mM}^{-1} \cdot \mathrm{s}^{-1}$ ], but a 30-fold improvement was obtained by addition of the 98-102 region to the sequence, bringing the substrate properties of $\kappa(98-112)$ close to those of whole $\kappa$-casein (Visser et al., 1980). In those studies no attempts were made to assign individual residues within this 98-102 sequence as being particularly responsible for the large jump in substrate quality.

Results from chemical modification and photooxidation experiments carried out on whole $\kappa$-casein (Hill \& Laing, 1965; Kaye \& Jollès, 1978) suggested a particular role of one or more of the three His residues (which are all located in the 98-102 fragment) in the formation of the enzyme-substrate complex. From the results of ionic-strength-dependence experiments done with whole $\kappa$-casein (Payens \& Both, 1980) and with the $\kappa(98-112)$ fragment (Visser et al., 1980), it was postulated that the positive charges at both sides of the Phe-Met bond (i.e. His and Lys residues) could be of

$$
\begin{array}{cccccccc}
\text {-His-Pro-His-Pro-His-Leu-Ser-Phe-Met-Ala-Ile-Pro-Pro-Lys-Lys- } \\
98 & 100 & 102 & 104 & 106 & 108 & 110 & 112
\end{array}
$$

From kinetic studies by Visser et al. (1976) it was concluded that $\kappa(103-108) \mathrm{OMe}$ represents the smallest peptide analogue of $\kappa$-casein with good substrate properties towards chymosin $\left(k_{\text {cat. }} / K_{\mathrm{m}}=22 \mathrm{~mm}^{-1} \cdot \mathrm{s}^{-1}\right.$ importance for electrostatic enzyme-substrate interactions (see also Payens \& Visser, 1981).

In the present study we have focused on the

\footnotetext{
Abbreviations used: $\kappa\left(n_{x}-n_{i j}\right)$, the $n_{x}-n_{i j}$ sequence of bovine $\kappa$-casein; OMe, methyl ester; Har, homoarginine; Nle, norleucine; NAc-His, $N^{\alpha}$-acetylhistidine; DEP, diethyl pyrocarbonate (ethoxyformic anhydride).

* To whom correspondence should be addressed.
} 
contribution to the formation of the enzyme-substrate complex of individual residues in the 98-102 region of the substrate and also of the Lys residues at positions 111 and 112. The latter form the nearest charged residues at the $C$-terminal side of the Phe-Met bond in $\kappa$-casein. In this study we used small synthetic $\kappa$-casein fragments having substitutions at the 102 position and also the 98-112 tryptic fragment (Visser et al., 1980) that had been chemically or enzymically modified in the $N$ and/or $C$-terminal part. Both the 98-102 and the 111-112 sequences are expected to include potential sites for interaction with counterparts outside but near the edge of the enzyme's active-site cleft.

\section{EXPERIMENTAL}

\section{Materials}

The peptide substrates $\kappa(101-108), \quad \kappa(102-108)$, $\kappa(103-108), \kappa(103-110)$ and $\kappa(103-112)$ or analogues of these sequences were synthesized by 'solution methods' as described by Schattenkerk et al. (1973). They were found to be homogeneous by t.l.c. The tryptic $\kappa(98-111)$ and $\kappa(98-112)$ fragments, isolated as described by Visser et al. (1980), were used as starting material for the modification experiments described below.

The chymosin preparation was the same as the one used in previous studies (Visser et al., 1976, 1977, 1980); its proteolytic activity towards Leu-Ser-Phe-Nle-Ala$\mathrm{IleOMe}$ as determined by u.v. spectrophotometry at $230 \mathrm{~nm}$ under specified conditions (Visser \& Rollema, 1986) amounted to $540 \mathrm{mkat} / \mathrm{kg}$.

\section{$C$-Terminal chain-shortening: preparation of $\boldsymbol{\kappa}(98-110)$}

A solution of $3.2 \mathrm{mg}$ of carboxypeptidase B (71 units $/ \mathrm{mg}$; Worthington Biochemical Corp.) in $2.3 \mathrm{ml}$ of

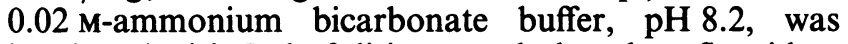
incubated with $5 \mu \mathrm{l}$ of di-isopropyl phosphorofluoridate (Fluka) for $24 \mathrm{~h}$ at room temperature. Then a solution of $100 \mathrm{mg}$ of $\kappa(98-111)$ or $\kappa(98-112)$ in $20 \mathrm{ml}$ of the above pH 8.2 buffer was added and the reaction mixture was kept at $30^{\circ} \mathrm{C}$ for $24 \mathrm{~h}$. After being freeze-dried, the product was taken up with $20 \mathrm{ml}$ of water and the solution was centrifuged. The supernatant was, in approx. $0.5 \mathrm{ml}$ portions, applied to a number of Sep-Pak $\mathrm{C}_{18}$ cartridges (Waters Associates) that had been pre-washed with methanol and water. The Sep-Pak columns were eluted with $5 \mathrm{ml}$ each of $15 \%, 50 \%, 75 \%$ and $100 \%$ methanol successively. The combined $50 \%$ methanol and $75 \%$-methanol fractions were, after evaporation and freeze-drying, re-chromatographed on Sep-Pak $\mathrm{C}_{18}$ in the same way. The fraction eluted with $50 \%$ methanol or (dependent on the recovery and the purity judged by t.l.c.) the combined $50 \%$-methanol and $75 \%$-methanol fractions were used for analysis and for the preparation of other substrates via $N$-terminal chain-shortening.

$N$-Terminal chain-shortening: preparation of $\kappa(99-110)$, $\kappa(100-110), \kappa(101-110)$ and $\kappa(102-110)$

The $\kappa(98-110)$ tridecapeptide (10-15 mg) obtained by the above procedure was used as starting material for one, two, three or four Edman degradation steps. Each step consisted of the following procedures.

Coupling. A solution of the peptide in $1 \mathrm{ml}$ of buffer (benzyldimethylamine/propan-1-ol/water, 3:10:12, by vol., adjusted to $\mathrm{pH} 9.4$ with acetic acid and kept under $\mathrm{N}_{2}$ ) was flushed with $\mathrm{N}_{2}$ in a vessel as described by Tarr $(1975,1977)$. Then $155 \mu \mathrm{l}$ of phenyl isothiocyanate (Sequenal grade; Pierce Chemical Co.) was added at $50^{\circ} \mathrm{C}$ and the solution was kept at this temperature for $40 \mathrm{~min}$ with occasional shaking (every $5 \mathrm{~min}$ ). Finally, the reaction mixture was dried at $50^{\circ} \mathrm{C}$ by flushing with $\mathrm{N}_{2}$.

Cleavage. The phenyl isothiocyanate derivative was taken up with $1 \mathrm{ml}$ of anhydrous trifluoroacetic acid (Eastman). After $10 \mathrm{~min}$ at $50^{\circ} \mathrm{C}$ the reaction mixture was dried at $50^{\circ} \mathrm{C}$ by flushing with $\mathrm{N}_{2}$.

Extraction. The residue of the cleavage reaction was taken up with a mixture of $200 \mu \mathrm{l}$ of water and $100 \mu \mathrm{l}$ of pyridine, and extracted twice with $500 \mu 1$ of benzene/ ethyl acetate $(1: 1, \mathrm{v} / \mathrm{v})$ or heptane/ethyl acetate $(1: 1, \mathrm{v} / \mathrm{v})$. The aqueous layer was evaporated to dryness.

After the last degradation step the product obtained was purified. To this end the residue of the extraction procedure was taken up with $1 \mathrm{ml}$ of water and applied to a Sep-Pak $\mathbf{C}_{18}$ cartridge. Elution was then carried out with water $(1 \mathrm{ml})$ and with $5-6 \mathrm{ml}$ each of $25 \%, 50 \%$, $75 \%$ and $100 \%$ methanol successively. The methanol fractions were evaporated to dryness under vacuum and checked for purity by t.l.c. The $50 \%$-methanol fraction was chosen for amino acid analysis and kinetic measurements.

\section{Modification of lysine residues: preparation of к(98-112, Har $\left.{ }^{111,112}\right)$}

2-Methylisourea (in the form of its sulphate; Fluka) was converted into its free base by adding $875 \mathrm{mg}$ in small portions to $20 \mathrm{ml}$ of a saturated aqueous solution of $\mathrm{Ba}(\mathrm{OH})_{2}$ with stirring, which resulted in a $\mathrm{pH}$ of 10.3 . The precipitate formed was centrifuged off and discarded. To $2.6 \mathrm{ml}$ of the freshly prepared reagent was added $20 \mathrm{mg}$ of $\kappa(98-112)$ and the solution was kept at $5{ }^{\circ} \mathrm{C}$ for 3 days (Kimmel, 1967). The reaction mixture was then acidified to $\mathrm{pH} 5.4$ by the addition of acetic acid, and the guanidated peptide was purified by ion-exchange chromatography on a $13 \mathrm{~cm} \times 1 \mathrm{~cm}$ column of SP(sulphopropyl-)Sephadex C-25 (Pharmacia) by using a gradient from 0.30 to $0.75 \mathrm{M}$-ammonium acetate buffer, $\mathrm{pH} 5.4$, essentially as described for $\kappa(98-112)$ by Visser et al. (1980). After repeated freeze-drying of the appropriate column fraction, the purity of the end product (yield $14 \mathrm{mg}$ ) was checked by t.l.c. and by amino acid analysis.

\section{Modification of histidine residues: preparation of ethoxyformylated $\kappa(98-112)$}

Ethoxyformylation was performed by reaction with DEP (Sigma Chemical Co.) and monitoring the progress of the reaction via the increase in absorbance at $240 \mathrm{~nm}$ (Ovádi et al., 1967; Mühlrád et al., 1967). The concentration of DEP in a stock solution was determined by its reaction (approx. $60 \mathrm{~min}$ at room temperature) with an excess of NAc-His dissolved in $0.05 \mathrm{M}$-sodium acetate buffer, pH 5.5. The molar absorptivity of the reaction product at $240 \mathrm{~nm}$ was derived from a series of incubations of NAc-His with increasing concentrations of DEP (DEP/NAc-His molar ratio 0.7-14:1). The absorbance measured after $15 \mathrm{~h}$ at room temperature in the above pH 5.5 buffer was for each incubation essentially the same as the one obtained after $1.5 \mathrm{~h}$ of reaction. The molar absorptivity was found to reach a 
maximum of approx. $4.0 \times 10^{3} \mathrm{M}^{-1} \cdot \mathrm{cm}^{-1}$ at a DEP/NAcHis molar ratio of $12-14: 1$.

Modification of $\kappa(98-112)$ was carried out as follows. To $6.5 \mathrm{ml}$ portions of the peptide solution $(67 \mu \mathrm{M})$ in $0.05 \mathrm{M}$-sodium acetate buffer, $\mathrm{pH} 5.5$, was added $152 \mu \mathrm{l}$ of ethanolic DEP solution of appropriate concentration. The final DEP/ $\kappa(98-112)$ molar ratio varied from $2.2: 1$ to $45: 1$, which corresponds to $0.7-15 \mathrm{~mol}$ of DEP per equivalent of His. After $1.5 \mathrm{~h}$ and again after $15 \mathrm{~h}$ at room temperature, duplicate samples were drawn for the determination of the amino acid content, the percentage modification and the initial cleavage by the action of chymosin.

T.l.c.

Samples were applied to ready-to-use silica gel (Merck $F_{254}$, thickness $0.25 \mathrm{~mm}$ ) or cellulose (Merck, thickness $0.1 \mathrm{~mm}$ ) plates. After development in butan-1-ol/acetic acid/pyridine/water (15:3:10:12, by vol.) the chromatograms were dried and sprayed with ninhydrin/collidine or with diazotized sulphanilic acid (Pauly reagent). The latter staining procedure is specific for histidine residues in the peptides concerned.

\section{Amino acid analysis}

Samples were hydrolysed with $6 \mathrm{M}-\mathrm{HCl}$ at $110^{\circ} \mathrm{C}$ for $24 \mathrm{~h}$ and $96 \mathrm{~h}$ in sealed evacuated tubes. Duplicate runs were made on a JEOL-5AH amino acid analyser with L-norleucine and L-2-amino-3-guanidinopropionic acid as internal standards for analysis on the long column and the short column respectively.

\section{Kinetic measurements}

The kinetics of enzymic cleavage were determined at

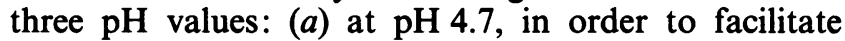
comparison with results obtained previously (Visser, $1981)$ with other substrates, $(b)$ at $\mathrm{pH} 6.6$, i.e. the $\mathrm{pH}$ of milk, and $(c)$ at an intermediate $\mathrm{pH}$ expected to be situated at or close to the optimum value for the cleavage of the substrate in question ('apparent pH optimum').

To check the general performance and reproducibility of the method, the substrate Leu-Ser-Phe-Nle-AlaIleOMe was included as internal standard in each series of kinetic measurements ( $\mathrm{pH} 4.7$ ).

Initial-rate measurements and data processing were performed as described in previous papers (Visser et al., 1976, 1980; Vreeman et al., 1977). Apparent pH optima were derived from theoretical bell-shaped curves fitted to experimental data expressing initial reaction rates as a function of $\mathrm{pH}$ determined at relatively low substrate concentrations (i.e. below the $K_{\mathrm{m}}$ value).

\section{RESULTS}

\section{Analysis of purity of substrates}

The results of amino acid analysis and t.l.c., used as a check of the efficiency of preparative Edman degradation, guanidation and ethoxyformylation, are shown in Table 1 and Fig. 1 respectively. It is seen that according to these criteria the various substrates are sufficiently pure, except $\kappa(102-110)$, which is obviously contaminated with some remaining $\kappa(101-110)$. Nevertheless, we have included this preparation in our comparative investigations of the effect of chain-shortening on the kinetics of chymosin action.

\section{Kinetic parameters}

Influence of chain-shortening and of guanidation. The kinetic parameters of chymosin action on enzymically or chemically modified $\kappa$-casein fragments are listed in Table 2. With this series of experiments it was aimed to study the influence of chain-shortening at either end of $\kappa(98-112)$ on the kinetics. It was presumed that for a proper comparison of kinetic parameters at any $\mathrm{pH}$ (for instance at $\mathrm{pH} 4.7$ or at the 'physiological' $\mathrm{pH}$ of 6.6) the (apparent) pH optima for the substrates in question

Table 1. Amino acid composition of some peptides tested as substrates for chymosin

Data are averaged results from $24 \mathrm{~h}$ and $96 \mathrm{~h}$ hydrolysates $\left(6 \mathrm{M}-\mathrm{HCl}, 110^{\circ} \mathrm{C}\right)$ except for serine and isoleucine, for which values from $24 \mathrm{~h}$ and $96 \mathrm{~h}$ hydrolysates respectively are reported. Numbers for guanidated $\kappa(98-112)$ were from a single analysis $(24 \mathrm{~h}$ hydrolysate).

\begin{tabular}{|c|c|c|c|c|c|c|c|c|c|c|}
\hline \multirow[b]{2}{*}{$\begin{array}{l}\text { Amino } \\
\text { acid }\end{array}$} & \multicolumn{10}{|c|}{ Amino acid composition (mol of residue $/ \mathrm{mol}$ ) } \\
\hline & $\kappa(98-112)^{*}$ & $\begin{array}{r}\kappa(98 \\
\text { eth } \\
\text { form }\end{array}$ & $\begin{array}{l}112) \\
x y- \\
\text { ated } \dagger\end{array}$ & $\begin{array}{c}\kappa(98-112) \\
\text { guanidated }\end{array}$ & $\kappa(98-111)^{*}$ & $\kappa(98-110)$ & $\kappa(99-110)$ & $\kappa(100-110)$ & $\kappa(101-110)$ & $\kappa(102-110)$ \\
\hline Ser & 1.0 & & & 0.9 & 0.9 & 0.9 & 0.9 & 0.9 & 0.9 & 0.9 \\
\hline Pro & 4.0 & & & 4.0 & 3.9 & 3.8 & 4.0 & 2.9 & 3.0 & 2.5 \\
\hline Ala & 1.0 & & & 1.0 & 0.9 & 1.0 & 1.0 & 1.0 & 1.0 & 1.0 \\
\hline Met & 1.0 & & & 0.9 & 0.9 & 1.0 & 1.0 & 1.0 & 0.9 & 1.0 \\
\hline Ile & 1.0 & & & 1.0 & 0.9 & 1.0 & 1.0 & 1.0 & 1.0 & 1.0 \\
\hline Leu & 1.0 & & & 1.0 & 1.0 & 1.0 & 1.0 & 1.0 & 1.1 & 1.0 \\
\hline Phe & 1.1 & & & 0.9 & 0.9 & 1.0 & 1.0 & 1.0 & 1.0 & 1.0 \\
\hline Lys & 2.0 & 2.0 & 2.0 & - & 1.1 & - & - & - & - & - \\
\hline His & 2.9 & 2.9 & 2.1 & 3.0 & 3.0 & 2.9 & 1.9 & 1.9 & 1.2 & 1.0 \\
\hline Har & - & - & - & 2.1 & - & - & - & - & - & - \\
\hline
\end{tabular}

* Used as starting material. Data are from Visser et al. (1980).

$\dagger$ Modified as described in the Experimental section, taking DEP/His ratios of 2.2:1 (left-hand column) and 15:1 (right-hand column). Only runs on the short column of the analyser (resulting in Lys and His values) were made. 


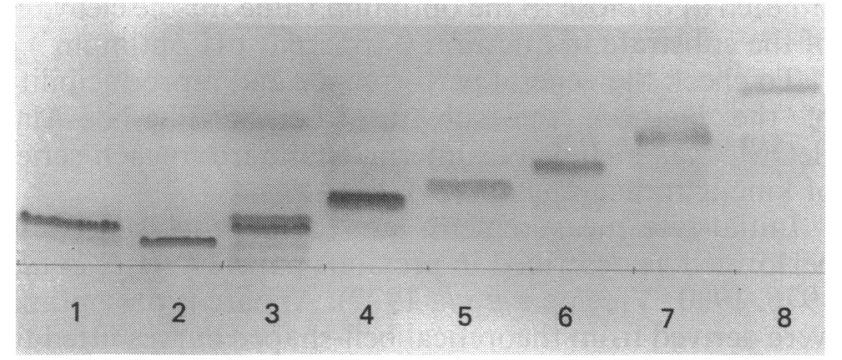

Fig. 1. Silica-gel t.l.c. patterns of peptide fragments obtained from bovine $\kappa$-casein by enzymic and chemical procedures

Staining was with Pauly reagent. For further experimental details see the text. Lane $1, \kappa\left(98-112, \mathrm{Har}^{111,112}\right)$; lane 2, $\kappa(98-112)$; lane 3, $\kappa(98-111)$; lane 4, $\kappa(98-110)$; lane 5, $\kappa(99-110)$; lane 6, $\kappa(100-110)$; lane $7, \kappa(101-110)$; lane 8 , $\kappa(102-110)$.

should be about the same. If the latter is not the case, a comparison of parameters exclusively near the optimum $\mathrm{pH}$ itself seems a better criterion. From Table 2 it is seen that guanidation of Lys-111 and Lys-112 (leading to a lengthening and a higher $\mathrm{p} K$ value of the side chain) does not greatly influence the kinetics of chymosin action. The same holds for the removal of Lys-112 from the $C$-terminal position. The presence of Lys-111 in the peptide chain seems to be more important, since elimination of this residue clearly decreases the substrate capacity (as mentioned above, in this case one should rather take into account exclusively the results obtained at the apparent $\mathrm{pH}$ optimum). It cannot be excluded, however, that, if we had replaced Lys-111 in $\kappa(98-112)$ by a non-positive residue, its binding function would have been (partly) taken over by Lys-112. Further chain-shortening from the $N$-terminal side, i.e. going from $\kappa(98-110)$ to $\kappa(102-110)$ in Table 2 , results in a gradual decrease of $k_{\text {cat. }} / K_{\mathrm{m}}$, predominantly caused by an increasing $K_{\mathrm{m}}$. The proteolytic constant of $320 \mathrm{~mm}^{-1} \cdot \mathrm{s}^{-1}$ found for $\kappa(102-110)$ at $\mathrm{pH} 4.7$ approaches the value of $105 \mathrm{mM}^{-1} \cdot \mathrm{s}^{-1}$ obtained previously (Visser et al., 1976) for the synthetic substrate $\kappa(103-110) \mathrm{OMe}$. The latter substrate represents one of the two longest and most susceptible peptide substrates found in that study under the same experimental conditions as the present ones. The results given in Table 2 do not suggest a predominant effect of one particular residue in the 98-101 region. It rather seems that the two His and the two Pro residues that were chemically removed from the peptide chain contribute to roughly the same extent to the overall substrate capacity.

Role of His-102. The possible role of His-102 in the enzyme-substrate complex was studied by testing some synthetic substrates in which Lys or Pro had been substituted at this position. The results of comparative measurements, carried out at $\mathrm{pH} 4.7$ as well as at the apparent $\mathrm{pH}$ optimum, are shown in Table 3. In these experiments it was presumed that the effect on the kinetics at $\mathrm{pH} 4.7$ of a Met $\rightarrow$ Nle replacement is the same for the hepta- and octa-peptide esters (Table 3, nos. 3 and 7) as for the hexapeptide esters (cf. nos. 1 and 2). It can be concluded that the replacement of His by Pro at

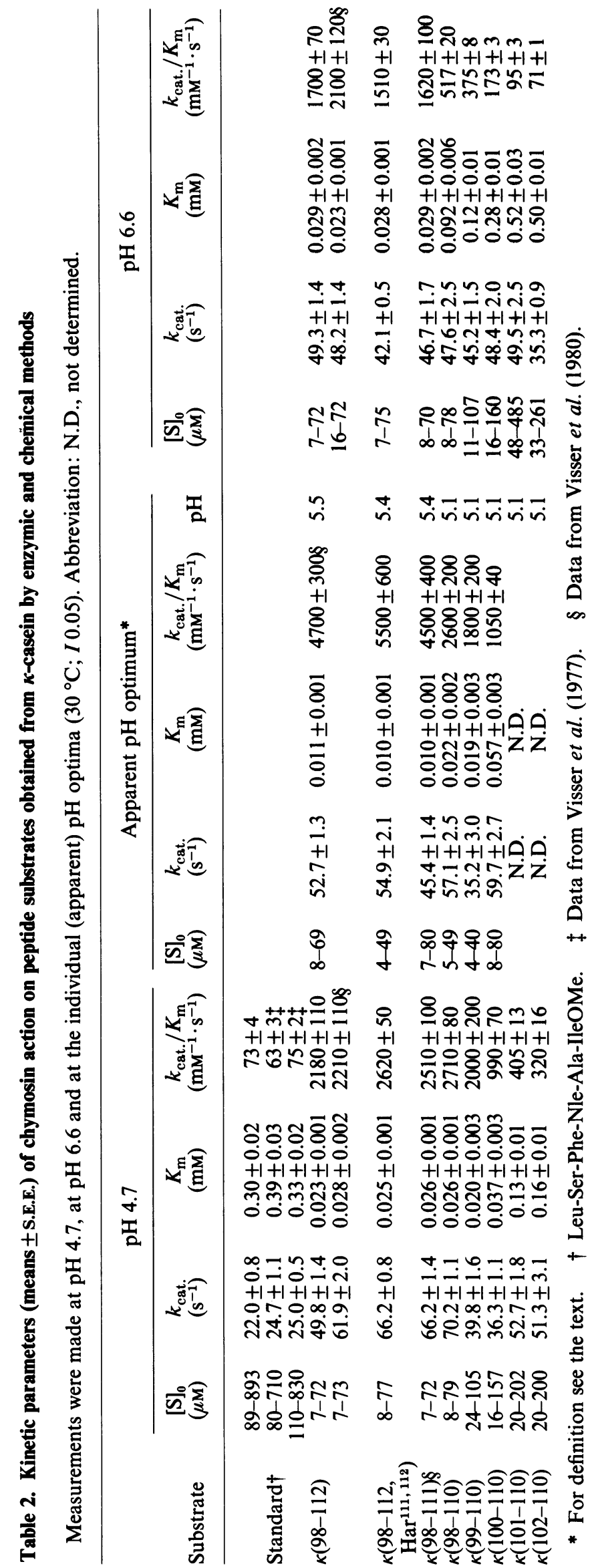

1987 
Table 3. Kinetic parameters $( \pm$ S.E.E.) of chymosin action on synthetic analogues of the $\kappa$-casein sequences $103-108,102-108$ and 101-108: influence of substitutions at position 102 of the sequence

Measurements were carried out at $\mathrm{pH} 4.7$ and at the individual 'apparent' $\mathrm{pH}$ optimum $\left(30^{\circ} \mathrm{C}, I 0.05\right)$.

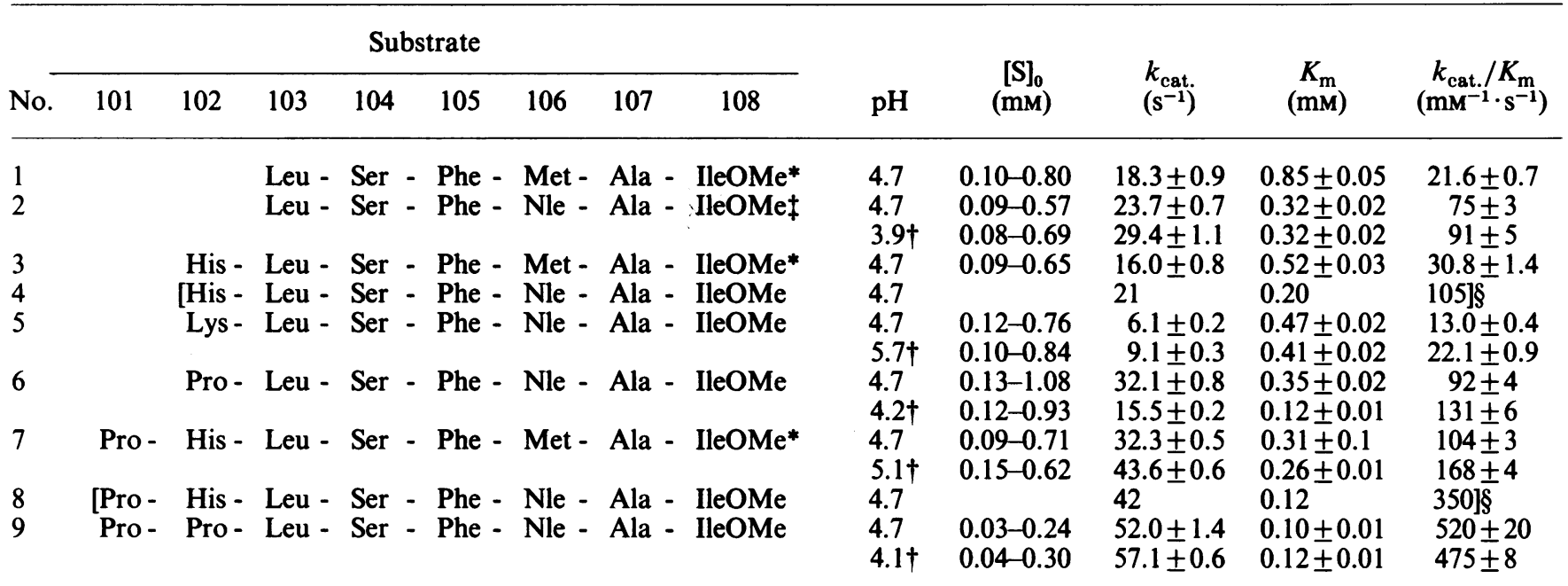

* Results obtained at pH 4.7 taken from Visser et al. (1976).

$\dagger$ Apparent pH optimum (see the text).

¥ Also used as internal standard substrate in this series (pH 4.7). See also Table 2.

$\S$ Kinetic parameters assumed to differ from those of the preceding substrate by a factor equal to that obtained for the Met $\rightarrow$ Nle replacement in the hexapeptide ester (cf. substrates nos. 1 and 2).

position 102 does not decrease the $k_{\text {cat. }} / K_{\mathrm{m}}$ value but at both $\mathrm{pH}$ values results in good to excellent substrate properties (Table 3, nos. 6 and 9). In contrast, replacement of His-102 by Lys leads to a diminished substrate behaviour (Table 3 , no. 5).

\section{Ethoxyformylation}

To investigate further the possible effect of the side chains of the various His residues on the substrate activity, we have modified these positions in $\kappa(98-112)$ by ethoxyformylation. The extent of modification (being virtually the same for $1.5 \mathrm{~h}$ and $15 \mathrm{~h}$ reaction periods) was calculated by taking a molar absorptivity of $4.0 \times 10^{3} \mathrm{M}^{-1} \cdot \mathrm{cm}^{-1}$ for the reaction product at $240 \mathrm{~nm}$. The effect of ethoxyformylation on the substrate activity of $\kappa(98-112)$ at $\mathrm{pH} 5.5$ is illustrated by Fig. 2. It is seen that, by an increasing (average) modification of His residues (effected by increasing DEP/His ratios in the reaction mixture), the substrate activity gradually decreases, but is not completely destroyed even when all three histidine residues have been ethoxyformylated.

\section{DISCUSSION}

To find out if and to what extent individual amino acid residues more remote from the cleavable $P$ he-Met bond of $\kappa$-casein contribute to the formation of the enzymesubstrate complex, we have chosen the approach of substrate modification. This was done in three ways: (a) use of synthetic $\kappa$-casein analogues in which one of the crucial residues had been replaced; $(b)$ chain-shortening of $\kappa(98-112)$ by chemical or enzymic procedures; $(c)$ chemical modification of one or more amino acid side chains in $\kappa(98-112)$. All these modifications resulted in well-defined products, the purity of which could be easily checked. A possible exception is the specific modification of $\mathrm{His}$ residues by ethoxyformylation. It is generally known (Miles, 1977) that results obtained via this procedure should be interpreted with caution, because of the possibility of simultaneous modification of residues other than His, and the risk of irreversible ring-opening of His side chains when a large excess of modifying reagent is used (Loosemore \& Pratt, 1976). The latter leads to an overestimation of the ethoxyformylated His residues as measured at $240 \mathrm{~nm}$. However, the occurrence of this side reaction can be tested by measuring the loss of His residues via amino acid analysis. Non-selectivity of the reaction of DEP with whole $\kappa$-casein was reported by Reimerdes \& Klostermeyer (1973). By carrying out the ethoxyformylation with a relatively short peptide having no or only a limited number of reactive groups other than histidine, one can avoid or at least better control this kind of side reaction. The modification of $\kappa(98-112)$, performed by carefully increasing the $\mathrm{DEP} / \mathrm{His}$ ratio in the reaction mixture, showed a destruction of His residues only at the highest DEP/His ratios used (cf. Table 1). The molar absorptivity of $4.0 \times 10^{3} \mathrm{M}^{-1} \cdot \mathrm{cm}^{-1}$ at $240 \mathrm{~nm}$ found for the reaction product of DEP and NAc-His is in agreement with the value of $3.9 \times 10^{3} \mathrm{M}^{-1} \cdot \mathrm{cm}^{-1}$ (at $242 \mathrm{~nm}$ ) reported by Choong et al. (1977) and is only a little higher than the $3.6 \times 10^{3} \mathrm{M}^{-1} \cdot \mathrm{cm}^{-1}$ (at $240 \mathrm{~nm}$ ) found by Holbrook \& Ingram (1973). The results of the experiment with ethoxyformylated $\kappa(98-112)$ disclose the involvement of His side chains of the substrate in its reaction with the enzyme. However, no predominant role of one particular His residue, as was suggested for whole $\kappa$-casein by Kaye \& Jollès (1978), could be established by our experiment. The apparent modification of more than the maximum of three His residues at higher DEP/His ratios (cf. Fig. 2 ) is in line with results obtained by Kaye \& Jollès (1978) with whole $\kappa$-casein. It should probably be ascribed to the above-mentioned destruction of imidazole groups.

Also, by the other modification procedures products 


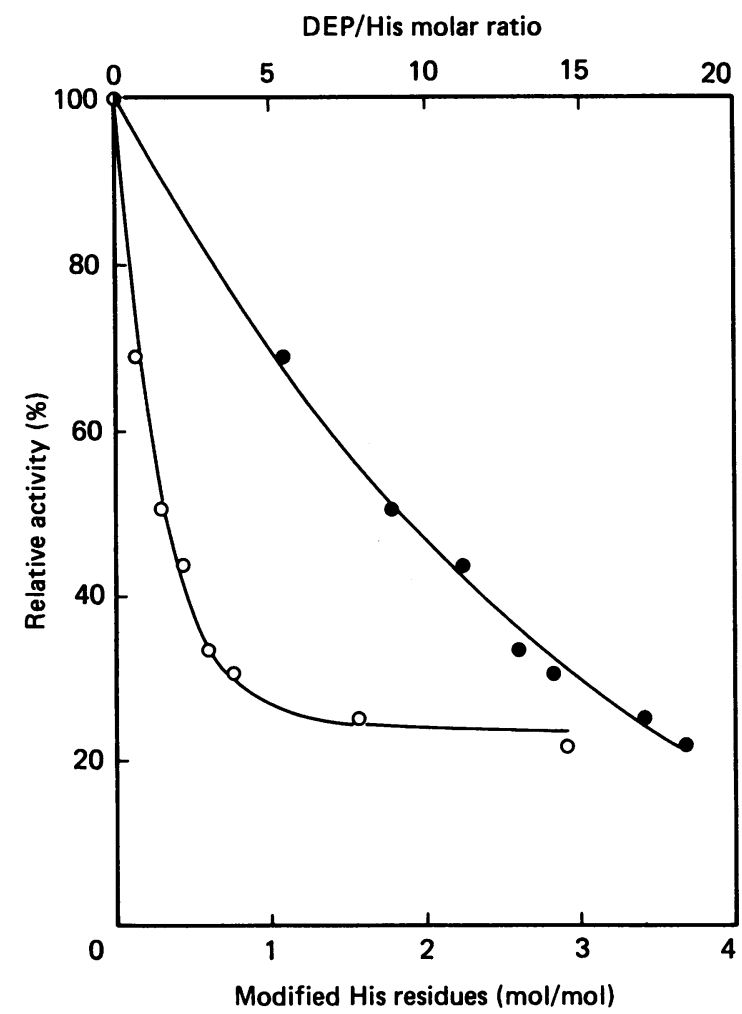

Fig. 2. Susceptibility of $\kappa(98-112)$ towards chymosin action at pH 5.5 as a function of the extent of modification by ethoxyformylation of histidine residues $(O)$ and as a function of the excess of DEP reagent used $(O)$

For experimental details see the text.

were obtained in which His residues appeared to have a binding function in the enzyme-substrate complex, as reflected by the $K_{\mathrm{m}}$ values measured. It should be noted, however, that interjacent Pro residues at positions 99 and 101 are at least as important in this respect and probably act in the same way as Pro-109 and Pro-110 as promoters of a proper positioning of the substrate part in the enzyme-substrate complex. Even the introduction of a Pro residue at the position of His-102 seems to stabilize the conformation of the enzyme-substrate complex equally well, whereas a Lys residue in this position forms an interfering factor.

In the enzyme-substrate complex the 103-108 sequence of the substrate is, as an extended structure (Raap et al., 1983), accommodated within the enzyme's active-site cleft. The hydrophobic Phe-105 and Met-106 side chains of the substrate as well as those of Leu-103 and Ile-108 are directed towards hydrophobic pockets along the wall of the active-site cleft, whereas the hydroxy group of Ser-104 forms part of a hydrogen bridge with some counterpart of the enzyme (Visser et al., 1976, 1977; B. L. Sibanda \& T. L. Blundell, unpublished work). The substrate parts immediately adjacent to the 103-108 fragment (i.e. the regions $98-102$ and 109-111) are forming $\beta$-turns (Raap et al., 1983) located around the edge of the active-site cleft in the enzyme-substrate complex. As was also put forward by Payens and his co-workers (Payens \& Both, 1980; Payens \& Visser,
1981), these parts contribute strongly to a firm and efficient binding to the enzyme molecule, thus making the Phe-Met bond of the substrate easily accessible to cleavage. It would be interesting to investigate further (for instance by minimizing the free energy of interaction in computer-modelling experiments) which negative charges on the enzyme part of the enzyme-substrate complex are candidates for interaction with the positive groups in the substrate regions discussed.

We are much indebted to Dr. Lynn Sibanda and Dr. Tom Blundell (University of London) for the information on their computer model of chymosin, and to Mrs. Cecile Schattenkerk (University of Leiden) for making the synthetic peptide samples available. We thank Dr. Henk Vreeman from this Institute for helpful discussions and critical remarks.

\section{REFERENCES}

Choong, Y. S., Shepherd, M. G. \& Sullivan, P. A. (1977) Biochem. J. 165, 385-393

Dalgleish, D. G. (1982) in Developments in Dairy Chemistry (Fox, P. F., ed.), part 1, pp. 157-187, Applied Science Publishers, Barking

Hill, R. D. \& Laing, R. R. (1965) J. Dairy Res. 32, 193-201

Holbrook, J. J. \& Ingram, V. A. (1973) Biochem. J. 131, 729-738

Kaye, N. M. C. \& Jollès, P. (1978) Biochim. Biophys. Acta 536, 329-340

Kimmel, J. R. (1967) Methods Enzymol. 11, 584-589

Loosemore, M. J. \& Pratt, R. F. (1976) FEBS Lett. 72, 155-158

Mercier, J. C., Brignon, G. \& Ribadeau Dumas, B. (1973) Eur. J. Biochem. 35, 222-235

Miles, E. W. (1977) Methods Enzymol. 47, 431-442

Mühlrád, A., Hegyi, G. \& Tóth, G. (1967) Acta Biochim. Biophys. Acad. Sci. Hung. 2, 19-29

Ovádi, J., Libor, S. \& Elödi, P. (1967) Acta Biochim. Biophys. Acad. Sci. Hung. 2, 455-458

Payens, T. A. J. \& Both, P. (1980) Adv. Chem. Ser. 188, 129-141

Payens, T. A. J. \& Visser, S. (1981) Neth. Milk Dairy J. 35, 387-389

Raap, J., Kerling, K. E. T., Vreeman, H. J. \& Visser, S. (1983) Arch. Biochem. Biophys. 221, 117-124

Raymond, M. N. \& Bricas, E. (1979) J. Dairy Sci. 62, 1719-1725

Raymond, M. N., Garnier, J., Bricas, E., Cilianu, S., Blasnic, M., Chaix, A. \& Lefrancier, P. (1972) Biochimie 54, 145-154

Reimerdes, E. H. \& Klostermeyer, H. (1973) Milchwissenschaft 28, 558-564

Schattenkerk, C., Holtkamp, I., Hessing, J. G. M., Kerling, K. E. T. \& Havinga, E. (1971) Recl. Trav. Chim. Pays-Bas 90, 1320-1322

Schattenkerk, C., Voskuyl-Holtkamp, I. \& Bokhorst, R. (1973) Recl. Trav. Chim. Pays-Bas 92, 92-116

Tarr, G. E. (1975) Anal. Biochem. 63, 361-370

Tarr, G. E. (1977) Methods Enzymol. 47, 335-357

Visser, S. (1981) Neth. Milk Dairy J. 35, 65-88

Visser, S. \& Rollema, H. S. (1986) Anal. Biochem. 153, 235-241

Visser, S., van Rooijen, P. J., Schattenkerk, C. \& Kerling, K. E. T. (1976) Biochim. Biophys. Acta 438, 265-272

Visser, S., van Rooijen, P. J., Schattenkerk, C. \& Kerling, K. E. T. (1977) Biochim. Biophys. Acta 481, 171-176

Visser, S., van Rooijen, P. J. \& Slangen, K. J. (1980) Eur. J. Biochem. 108, 415-421

Vreeman, H. J., van Rooijen, P. J. \& Visser, S. (1977) Anal. Biochem. 77, 251-264 